\title{
Experimental Study on Shear Performance of Bolt in Roadway Supporting
}

\author{
D.J. Li ${ }^{12^{*}}$, Z.L. Ding ${ }^{2}$, C.L. Li ${ }^{3,4}$ and J.H. Chen ${ }^{5}$ \\ ${ }^{1}$ State Key Laboratory for GeoMechanics and Deep Underground Engineering, Beijing 100083, China \\ ${ }^{2}$ School of Mechanical and Civil Engineering, China University of Mining \& Technology, Beijing 100083, China \\ ${ }_{3}^{3}$ School of Civil Engineering and Mechanics, Yanshan University, Qinhuangdao 066004, China \\ ${ }^{4}$ Institute of Urban Construction, Hebei Normal University of Science \& Technology, Qinhuangdao 066004, China \\ ${ }^{5}$ School of Mining Engineering, University of New South Wales, Sydney, 2052, Australia
}

Received 26 March 2014; Accepted 29 August 2014

\begin{abstract}
The corner bolt is proved to be effective in the control of floor deformation of roadway, and the relevant studies on bolting mechanisms are of great significance in improving roadway stability. In this paper, two types of shear tests on six forms of bolts are performed by using self-designed shear test device, the electro-hydraulic servo triaxial testing system. The shear characteristics of different types of bolts are obtained. The results show that different bolt rods or different internal filling conditions result in large differences in shear resistance and different deformation adaptability. We find that the filling materials added can improve the shear performance of bolt significantly, and the bolt with steel not only can improve the strength of bolt body, but also has the bimodal characteristic that makes the bolt have the secondary bearing capacity and withstand larger deformation range during the process of shear, and shows a better support performance. Hoping to provide the experiment basis for support design and field application in the future.
\end{abstract}

Keywords: Roadway, Corner Bolt, Shear Test, Support, Deformation Mechanism

\section{Introduction}

As an important support component in rock engineering, bolts make a positive contribution to the change of strength and deformation performance of the rock [1]. These bolts buried in underground chambers of the surrounding rock are often subjected to loads including of shear or tension or both of them. Therefore, they must be able to withstand both large enough shear and tension [2]. So the studies on deformation characteristics of bolts under shear loads are of great significance for maintaining stability of surrounding rocks [3-4].

With the increase of the mining depth, the deep rock masses are in the "three high and one disturbance" complex conditions [5]. In the process of floor heave, the damage of these bolts buried not only accentuates the maintenance work and cost, but also threatens the safety production of deep coal mining [6].

During the roadway excavation, the stress redistribution causes a forward movement of floor toward the free face of roadway, and at this time the floor heave phenomenon appears. Generally accompanied by the roof subsidence, large displacement occurs in both sides of the roadway with shear deformation, making bolts in the jointed rock under tension and shear state [3].

The bolts at the floor corner are set at an angle into the rock to control the floor heave. Corner bolts mainly play two

\footnotetext{
*E-mail address: lidj@cumtb.edu.cn

ISSN: 1791-2377 (C) 2014 Kavala Institute of Technology. All rights reserved.
}

roles as follows [7]: One is to control the development of plastic zone on the roadway floor and weaken the stress concentration at the corner and form the bearing arch with higher self-supporting capability at the base corner, that can pass the axial load to the corner bolt and make the high stress transfer to the deep rock masses. Another is to effectively cut off the plastic slip lines from both sides of the roadway and weaken the compressive stress in both sides to control the floor heave deformation.

In recent years, extensive studies on shear properties of bolt have be carried out in domestic and overseas [8-9]. Using shear apparatus in double jointed concrete anchor unit, Grasselli performed shear tests on full-length anchoring and expansion anchoring, and found the plastic hinge in shearing process would delay the increase of stress levels, the expansion bolt had the larger ability of deformation [10]. $\mathrm{Gu}$ found that the morphological changes in the cell wall had a greater impact on the bearing capacity of bolts [11]. Li et al. established anchorage models of rock mass and the bolts [12-14].

The engineering practices indicate that the materials of corner bolts should be of good bending, shear and tensile properties in order to fully inhibit the process of floor heave. At present the whorl-steel bolts widely used in the roof and side-wall of coal roadways are difficult to meet the support requirement under deep mining conditions. In order to satisfy those engineering mechanical properties, it is necessary to develop a kind of new type bolt using new materials.

In this paper, six kinds of different bolts are selected to study their shear characteristics, and this study will provide an experimental basis not only for the study of mechanical 
properties of corner bolts, but also for the parameter optimization design, and it also helps us understand the prevention mechanism of floor heave.

\section{Shear Test on Bolts}

There are two classes (seamless pipe, seamed pipe) of shear tests on six kinds of bolts. The basic information of the bolts is shown in Table 1.

The test equipment is XTR01 microcomputer controlled system, the electro-hydraulic servo triaxial rock test system, developed by the State Key Laboratory for GeoMechanics and Deep Underground Engineering, China University of Mining Science \& Technology (Beijing). According to the test requirement, the metal bearing is designed to fix the bolt and it is placed between the lower piston and the upper plate in the shear test. The photos of test are shown in Fig. 1.

The test process is described as follows: Firstly, intercepted a about $300 \mathrm{~mm}$ long bolt and inserted its both ends into the rigid indenter in the bearing, and high-strength bolts was used to fix the rigid indenter and compressed tightly the bolt. Secondly, the indenter was placed in the middle of the bolt, and the indenter width was less than the distance between two fixed ends of support structure $2 \mathrm{~mm}$ $4 \mathrm{~mm}$. Thirdly, to start the pressure machine and the pistons evenly rise until the rigid indenter held the rigid upper plate. Finally, through the rigid indenter the load was transferred to the bolt, and the bolt received the shear force. The load rate was controlled by a piston displacement rate of $0.05 \mathrm{~mm} / \mathrm{s}$. During the test the value of the load and deformation were automatically collected in the process of shear by the axial pressure sensor and the computer.

Table1. Basic information of test bolts

\begin{tabular}{|c|c|c|c|}
\hline Classification & No. & $\begin{array}{l}\text { Diameter } \\
/ \mathrm{mm}\end{array}$ & Filling case in the bolt \\
\hline \multirow{3}{*}{ Seamless bolts } & $\mathrm{NP}_{1}$ & $\varnothing 42$ & No filling \\
\hline & $\mathrm{NP}_{2}$ & $\varnothing 42$ & C20 Cement mortar filling \\
\hline & $\mathrm{NP}_{3}$ & $\varnothing 42$ & $\begin{array}{l}\text { C20 Cement mortar filling } \\
\text { with } \varnothing 12 \mathrm{~mm} \text { HPB235 steel } \\
\text { bar }\end{array}$ \\
\hline \multirow{3}{*}{ Seamed bolts } & $\mathrm{CP}_{1}$ & $\varnothing 43$ & No filling \\
\hline & $\mathrm{CP}_{2}$ & $\varnothing 43$ & C20 Cement mortar filling \\
\hline & $\mathrm{CP}_{3}$ & $\varnothing 43$ & $\begin{array}{l}\text { C20 Cement mortar filling } \\
\text { with } \varnothing 12 \mathrm{~mm} \text { HPB235 steel } \\
\text { bar }\end{array}$ \\
\hline
\end{tabular}

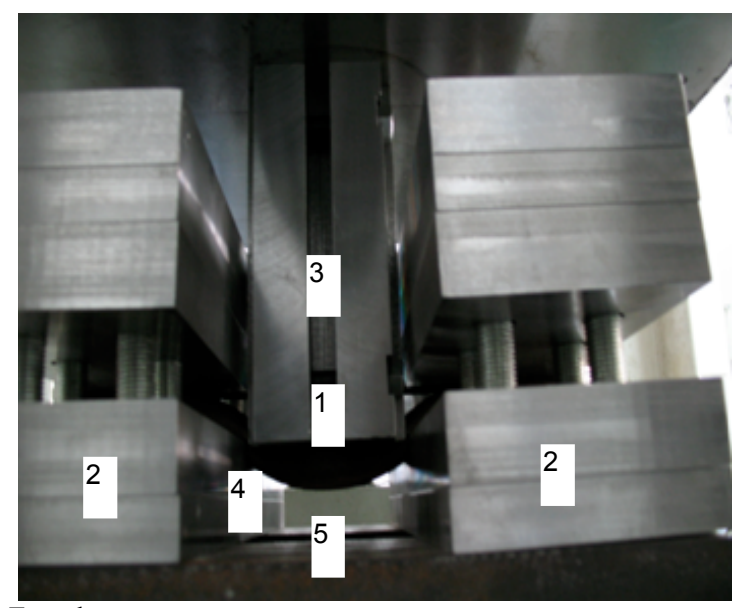

(a) Test photos

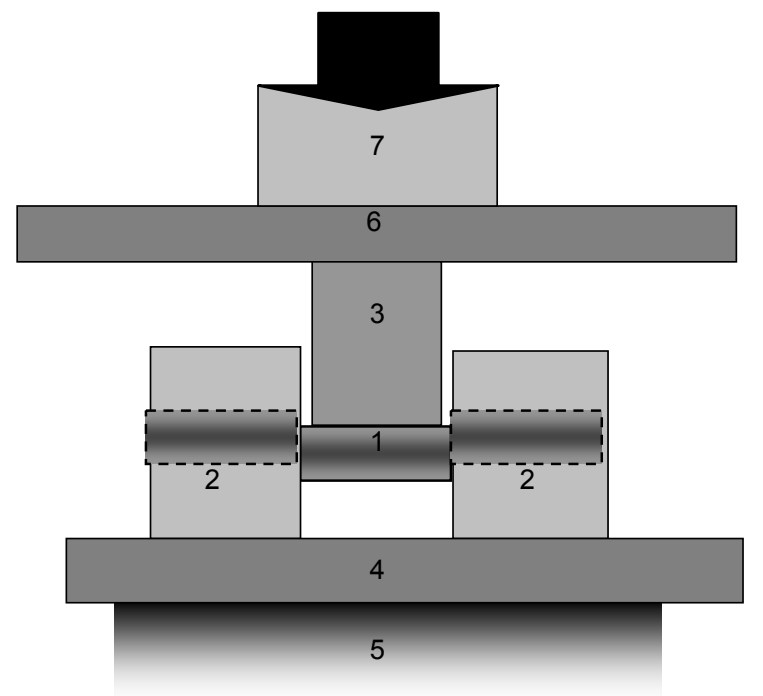

(b) Bracket structure

1-Bolt, 2-Rigid indenter, 3- Indenter, 4-Bearing, 5- Lower piston, 6upper plate, 7- Axial pressure sensor.

Fig.1. The shear test on Bolts

\section{Test Results and Analysis}

The sectional photos of fractured test specimen are shown in Figs. 2 and 3, it can be seen that the sectional fracture of the broken bolts are neat, belonging to a typical shear failure mode.

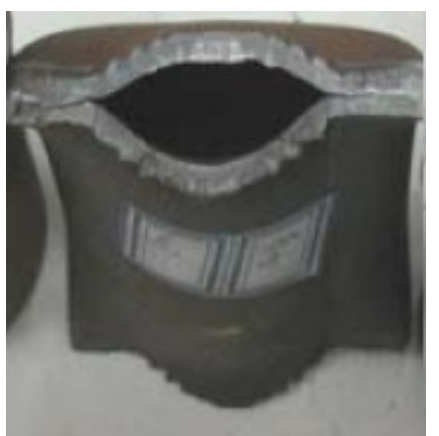

(a) Hollow $\left(\mathrm{NP}_{1}\right)$

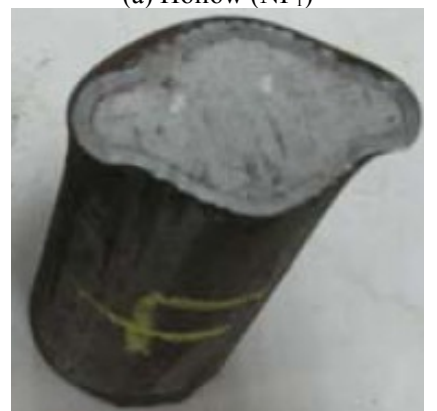

(b) Grouting $\left(\mathrm{NP}_{2}\right)$

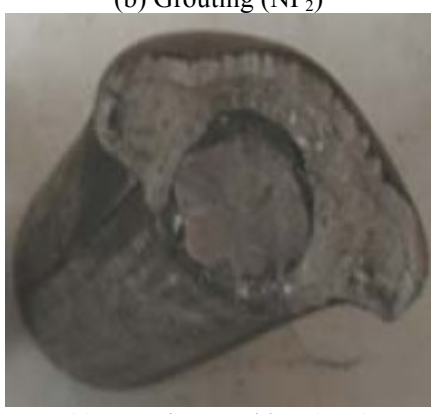

(c) Inserting steel bar $\left(\mathrm{NP}_{3}\right)$

Fig.2. Shear fracture photos of bolts without seam 


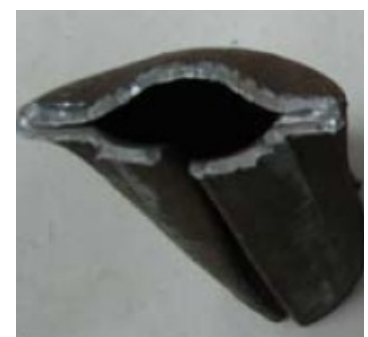

(a) Hollow $\left(\mathrm{CP}_{1}\right)$

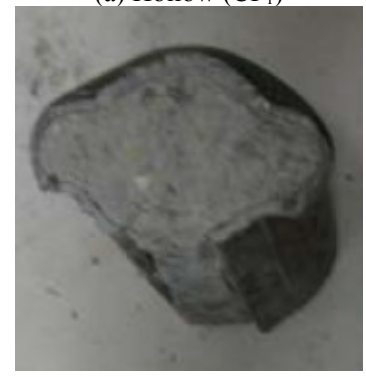

(b) Grouting $\left(\mathrm{CP}_{2}\right)$

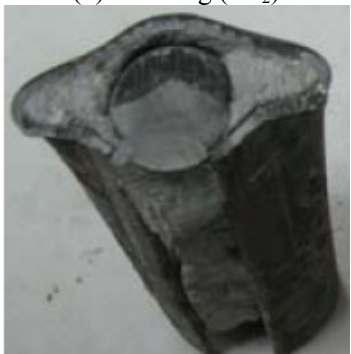

(c) Inserting steel bar $\left(\mathrm{CP}_{3}\right)$

Fig. 3. Shear fracture photos of bolts with seam

The shape of cross section of bolt changed from circular to oval during the shearing process, and then the bolt entered the shear stage. The cross-section deformation and the shear loads were affected by the filling materials of the bolt, and the bolts with different filling materials exhibited different shear characteristics.

Load-displacement curves are shown in Fig. 4. From the process of shearing of the seamless and seamed bolts, it can be seen that the ultimate shear load of the bolt with steel is the largest, and the shear load of grouting bolt takes the second place, the shear ultimate load of hollow bolt is the smallest.

Two peaks of load of the bolt with steel bar $\left(\mathrm{NP}_{3}, \mathrm{CP}_{3}\right)$ occur during the shear process, the first peak load $\left(\mathrm{Q}_{3}\right)$ represents the ultimate load when the overall bolt break, the second peak load $\left(\mathrm{Q}_{3}{ }^{\prime}\right)$ represents the strength when the bolt rod and pipe shell are broken, and at this time the steel bar has not completely been cut off, and the load continues to increase and gradually reached the residual shear strength of reinforcement, therefore, the second load peak value is substantially the same with the $\mathrm{Q}_{2}$ in the $\mathrm{NP}_{2}$ type.

In the seamless and the seamed bolt, the shear strength of the bolt with steel bars is the maximum value and that of the hollow bolt is the minimum, the grouting bolt is between them. The loading-deformation curves experience three stages which can be judged by condition of the filling material in the pipe.

Stage 1 is the small elastic deformation stage, that is corresponding to the section from the test starting point to the A point of the load-deformation curves, and in this stage the load-deformation curves basically show a linear relationship and the shear stress increases rapidly.
For the seamless bolts the effects of filling materials are not big and these curves are consistent in the initial elastic phase (Fig. 4a). For the seamed bolt (Fig. 4b), in the elastic deformation stage the impact of different filling forms is obvious, and the elastic ultimate load of the bolt with steel bar is the maximum and reaches approximate $140 \mathrm{kN}$, and that of the hollow bolt is the minimum and reaches approximate $50 \mathrm{kN}$, and that of the grouting bolt is between them and reaches approximate $90 \mathrm{kN}$,
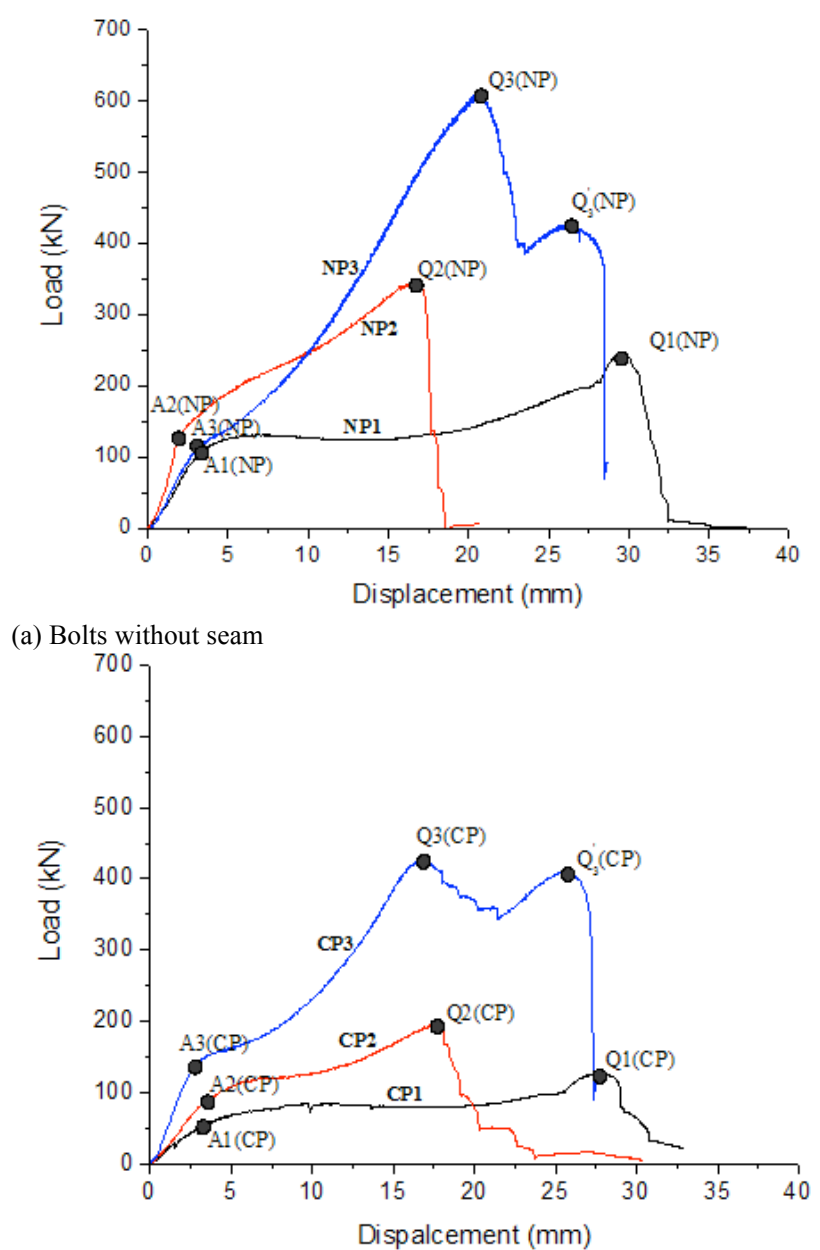

(b) Bolts with seam

Fig.4. Load-deformation curves of the bolts

Stage 2 is the nonlinear yield deformation stage, that is corresponding to A point to Q point in the load-deformation curves under the uniform deformation condition, comparing with the first stage the loading rate of shear decreases in different extent until reaching the peak load.

The section shape of bolt begins to change significantly, which delays the increases of shear stress and causes the plastic slip, and the plastic hinge appears in the shear parts.

Stage 3 is the shear and rupture stage, and in this stage the load deformation curves sharply decline from the peak $\mathrm{Q}$ point, and the bolt body fractures and comes into the unstable fracture process with the increase of plastic deformation.

In the uniform deformation process, after the section shape changes the shearing stage is coming. It is obvious that the deformation and the shear load are affected by the filling material properties.

As shown in Fig. 4, the deformation characteristics of different types of bolts with the same filling materials are 
similar. Because of the stiffness influence of filling material, the difference between the yield value of hollow bolt and the yield value of grouting bolt is significant, the stiffness of bolts with different filling materials correspondingly are increased in different degrees.

Comparing the different bolts with the same filling material in shear deformation curves, it can be concluded that:

In the hollow bolt, the shear performance of seamless bolt is better than that of the seamed bolt. But after entering the plastic stage the cross-sections of the two kinds of bolts reach a large deformation, until the bolts on both sides are compressed, then the bolts enter the shear failure stage, and the second peak load emerges, as shown in Fig. 4.

The grouting bolt shows a better shear performance, the shear modulus of the bolt has been greatly improved, while the amount of deformation corresponding to the peak intensity value is smaller, the deformation adaptability of the bolt reduces.

The shear performance of the bolt with steel bar obviously improves. The bimodal load phenomenon occurs in the process of shear test. The first peak load is corresponding to the strength value when the whole bolt is cut off; the second load peak is corresponding to the residual strength of steel bar after the bolt wall is cut off.

Different bolts' fracture is in different forms. As can be seen from Fig. 3, the sectional shape of a circular hollow bolt become elliptic after deformation, after both sides of tube wall contact and extrusion, the bolt shear fracture. Where the reinforced bolt fracture, there is no complete loss of the bearing capacity like the other bolts. But the bearing capacity decrease about $30 \%$, and the steel bars continue bearing the shear force until the steel bars fracture and completely lost the bearing capacity.

As can be seen from shear loads and deformation characteristic curve of the different bolts, the overall stiffness of the seamless bolt is greater than the seamed bolt, especially to the reinforced bolt, the shear strength and the stiffness had been greatly improved, as is shown in Table 2 .

Table 2. Shear test results of different bolts

\begin{tabular}{llcc}
\hline \multirow{2}{*}{ Classification } & No. & $\begin{array}{c}\text { Shear load } \\
(\mathrm{kN})\end{array}$ & $\begin{array}{c}\text { Load increase rate } \\
(\%)\end{array}$ \\
\hline \multirow{3}{*}{ Seamless bolts } & $\mathrm{NP}_{1}$ & 230 & - \\
\cline { 2 - 4 } & $\mathrm{NP}_{2}$ & 340 & 47 \\
\cline { 2 - 4 } & $\mathrm{NP}_{3}$ & 600 & 76 \\
\hline \multirow{2}{*}{ Seamed bolts } & $\mathrm{CP}_{1}$ & 120 & - \\
\cline { 2 - 4 } & $\mathrm{CP}_{2}$ & 190 & 58 \\
\cline { 2 - 4 } & $\mathrm{CP}_{3}$ & 420 & 191 \\
\hline
\end{tabular}

After the roadway excavation, the bolts are installed with an angle into the roadway floor, which could effectively decompose the rock vertical stress from both sides of rock mass along the vertical axis and the normal, weaken the impact of vertical stress on the floor. From the results of the two kinds of bolts shear tests, the seamless bolt with steel not only provides strong support in the surrounding rock, but also provides a space for the surrounding rock deformation. Different from the common sense of yield deformation, the seamless bolt itself have high strength, to some extent the large deformation characteristics conformed to the adjustment process of the confining stress distribution, so the centralized stress transferred to the deep rock mass, to satisfy the stress and deformation conditions to constrain floor heave.

The load bimodal phenomenon of the inserting steel bar bolt occur in the shear process, this feature could effectively prevent the plastic slip of the jointed rock. With the increase of rock deformation, the shear force of the bolt have been increasing, the deformation energy of the surrounding rock mainly converted to deformation energy of the bolt system. The bolt could continue to consume the rock deformation energy, once the rock deformation continued to increase, the overall bolt fractured, the reinforced bolt had not yet broken and could still continue to resist the deformation of rock mass. Until the second load peak the steel fractured, and the bolt failure overall.

The reinforced bolt not only could improve the bolt body's own strength and deformation range, but also the bimodal characteristic during the process of shear make the bolt could bear the secondary load. For the repairing roadway, the initial deformation had released the stress of the surrounding rock, depending on the actual situation, may select the somewhat less shear resistance of the corner bolt form, such as no filling material seamless or seamed bolt. While for the newly excavated roadway, the stress concentration degree is high and the initial deformation is large, the corner bolt is recommended to use the material with good shear resistance, such as seamless bolt with steel.

From the results of two kinds of bolts shear tests, due to the large diameter and the slotted structure, easy to adjust the length, the seamed bolt with steel mainly rely on the friction force to achieve full-length anchoring, but its shear strength is less than the seamless reinforced bolt. Seamless reinforced bolt not only provide strong support to the surrounding rock, but also provide a larger space for the surrounding rock deformation. Different from the common sense of yield deformation, the seamless bolt could effectively decompose the vertical stress from two sides of rock along the bolt axial and the normal direction, and weaken the effect of vertical stress on the bottom. The high strength and large deformation characteristics to some extent conform to the adjustment process of confining stress distribution, the centralized stress transfer to the deep rock mass, to satisfy the stress and the deformation conditions to constrain the floor heave.

The seamless bolt and the seamed bolt with steel in the shear process have the loading bimodal characteristics, and the characteristics could effectively prevent both sides of the jointed rock mass plastic slip and could adapt the greater deformation of the roadway. It should be noted that, the coupling support between the bolt system and the rock is a key problem in design. In this paper, we hope that the results could provide the basis for prevention and treatment of the floor heave and optimization design parameters of bolt.

\section{Conclusion}

The load-deformation curves of the seamless and the seamed bolts are obtained, and the seamless bolt shear capacity is higher than the seamed bolt shear capacity.

For the same kind of bolt, the filling materials of bolt have a greater impact on the shear behavior. The reinforced bolt with steel could be greatly improved the shear resistance, grouting bolt followed by the second, and the hollow bolt is the smallest in shear resistance.

The reinforced bolt with the steel could improve the strength and deformation, and the bimodal load 
characteristics in the process of shear could ensure the shear bolt withstand a large amount of deformation in certain shear strength.

The filling materials have great influence on the shear performance, and the bolt shear properties could meet the requirements of controlling the floor heave under different conditions.

\section{Acknowledgement}

The study is conducted in State Key Laboratory for GeoMechanics and Deep Underground Engineering, China University of Mining Science \& Technology, Beijing.

The postgraduate student, C.G. Wang, H.X. Wang of Graduate School of China University of Mining Science \&
Technology, Beijing, had carried on the related experimental work together and the Professor M.C. He, Z.B. Guo of China University of Mining Science \& Technology, Beijing, who had provided information of the project, all these deserve deep thanks by the authors.

The National Key Basic Research Program (973 Program) (2010CB226800), the Innovation Team Development Program of the Ministry of Education (IRT0656), the fundamental research funds for the central universities (00-80015I2: 2010YL14), the National Natural Science Foundation of China (51474188, 51074140, 51310105020), and the Natural Science Foundation of Hebei Province of China (E2014203012) funded us, all these are gratefully acknowledged.

\section{References}

[1]. Wu Y.-L., Wang Y.-H. and Xu M.-G., "Effect of Bolt in Jointed Rock Mass under Mixed Loading of Tension and Shearing", Chinese Journal of Rock Mechanics and Engineering, 22 (5), 2003, pp. 769-772. (in Chinese)

[2]. Ludvig B. and Li D., "Shearing Test of Bolt", Yangtze River, 4, 1987, pp. 51-58. (in Chinese)

[3]. Stankus J., Peng S., "Floor Bolting for Control of Mine Floor Heave", Mining Engineering, 46 (9), 1994, pp. 1099-1102.

[4]. Lazić V.-L., Arsić M., Šarkoćević Ž., Sedmak A. and Rakin M., "Structural life assessment of oil rig pipes made of API J55 steel by high frequency welding", Tehnicki vjesnik-Technical Gazette, 20 (6), 2013, pp. 1091-1094.

[5]. He M.-C., "Conception System and Evaluation Indexes for Deep Engineering", Chinese Journal of Rock Mechanics and Engineering, 24 (16), 2005, pp. 2854-2858. (in Chinese)

[6]. Wang S.-R., He M.C. and Fan X.M., "Technique of Bolt-net Supporting for Gateway with JS Composite Roof", Journal of University of Science and Technology Beijing, , 27 (4), 2005, pp. 390-394. (in Chinese)

[7]. Yang S.-B., He M.-C., Liu W.-T. and Ma X.-J., "Mechanics and Application Research on The Floor Anchor to Control The Floor Heave of Deep Soft Rock Roadway", Chinese Journal of Rock Mechanics and Engineering, 27 (S1), 2008, pp. 2913-2920. (in Chinese)
[8]. Rong G., Zhu H.-C. and Zhou C.-B., "Testing Study on Working Mechanism of Fully Grouted Bolts of Thread Steel and Smooth Steel", Chinese Journal of Rock Mechanics and Engineering, 23 (3), 2004, pp. 469-475. (in Chinese)

[9]. Song Z.-F., Xu B. and Song H.-Q., "The Interfacial Mechanical Characteristics in Anchorage Zone of Grouted Bolts", Journal of China Coal Society, 33 (9), 2008, pp. 988-991. (in Chinese)

[10]. Grasselli G., "3D Behaviour of Bolted Rock Joints: Experimental and Numerical Study", International journal of rock mechanics and mining sciences, 42 (1), 2005, pp. 13-24.

[11]. Gu L.-Y., Xu J.-M., Gu X. and Li X.-F., "Effect of Geometric Wave Shape of Anchor Cable Borehole Wall on Its Bearing Capacity", Chinese Journal of Rock Mechanics and Engineering, 24 (20), 2005, pp. 173-178. (in Chinese)

[12]. Li C. and Stillborg B., "Analytical Models for Rock Bolts", International Journal of Rock Mechanics and Mining Sciences, 36 (8), 1999, pp. 1013-1029.

[13]. Cai Y., Esaki T. and Jiang Y., "A Rock Bolt and Rock Mass Interaction Model", International Journal of Rock Mechanics and Mining Sciences, 41 (7), 2004, pp. 1055-1067.

[14]. Wang S.-R., He M.-C. and Jin Y.-J., "Anchoring Mechanism of PACDP and PACCT Anchor Cable", Journal of University of Science and Technology Beijing, 27 (3), 2005, pp. 278-282. (in Chinese) 